inspection of the bones showed that the animal was nearly adult. The general growth of the other thigh in the first $\mathrm{dog}$, and of the opposite forearm in the other two, was found to correspond with the limbs operated on.

Although there were only three animals operated on, the results obtained were consistent. From the measurements just given, it appears that in the limbs of half-grown dogs of the terrier type the total increase in the length of the long bones may be estimated at about one-tenth of their whole length in three months. A forearm, for example, of 5 in., would be $5 \frac{1}{3}$ in. at the end of that time. Further, of that growth by far the larger part was due to, and took place at the epiphyses. This might be taken at quite four-fifths of the whole increase, but there was also a demonstrable growth going on throughout the length of the shaft, which, in the case of the limb supposed, would in three months amount to $\frac{1}{10}$ in., or onefifth of the total increase, the remaining four-fifths taking place at the epiphyses.

If it is permissible to form any opinions as to human growth of bone from that which is found in the dog, it would seem that it is reasonable to recognise that the essential increase of the diaphysis in young bones may well be of importance as affecting the processes by which - deformities are produced or rectified. I have these bones here for inspection, and have marked on the card the exact distances between the incision marks at the time they were made. The increase in the bones can readily be seen, but not nearly so well as when they were quite fresh, for the Indian ink then still stained the immedlate area of operam tion, and there was a little callous thickening of periosteum at the incision, which has hardly survived the maceration.

\section{CASE OF RENAL CALCULUS.}

NEPHPECTOMY PERFORMED BY MR. BARWELL NINE YEARS AGO ; IMPACTION OF CALCULUS IN URETER OF THE OTHER KIDNEY, FOLLOWED BY NON-OBSTRUCTIVE JAUNDICE $\Lambda$ ND DEATH.

BY FREDK. W. MOTT, M.D., B.S., M.R.C.P., ASSISTANT PHYSICMN, LATE MENICAL REGISTRAR, CHARING-CROSS HOSWTAL.

D. $\mathrm{F}-$, aged twenty-six, was admitted into Charingcross Hospital on March 28th, 1890, under the care of Dr. Green. He stated that his left kidney had been removed by Mr. Barwell on May Ist, 1881, and I find the following among the abstracts of the communications made to the International Medical Congress of that year: "Nephrectomy for nephrolithiasis, by R. Barwell, F.R.C.S.-Dennis F., aged 18, was under my care in October, 1880, with a left Iumbar abscess, diagnosed as perinephritic, probably depending on calculus. The abscess was widely opened. Heimproved in health. No leave for further measures was obtained. He was discharged in January, 1881, but kept under observation. On March 29th, 1881, the lad was readmitted, having suffered more and lost tlesh considerably. His tem perature was very hectic. In April I sounded through the persistent sinus and detected as stone. On May 5th leave for further procedure was obtained. The difficulties foreseen were from proximity of the twelfth rib to the erest of the ilium, and from the amount of dense cicatricial tissue." Mr. Barwell then describes the operation by which he successfully removed the organ. "June 22nd": The boy is well in health. Has gained flesh; temperature normal. Only a minute wound appears." Since the summer of 1881, up to March 21 st, 1890 , when the present illness commenced, he has been in good health and followed the occupation of bookedge gilder.

Present Illness. - On March 22nd, a week previously to admission, the man was seized with severe vomiting great pain at the epigastrium, and "feeling of illness and feverishness," which obliged him to take to his bed. On March 24th he came to the out-patient department complaining of great pain in the right side. He was seen by Dr. Frederick Willcorks, who examined the urine and found pus and albumen. He suggested that there was probably a stone in the other kidney, and told him if he became worse to come at once to the hospital. On the 27 th the patient noticed a lump in the right loin, which did not give him nuch pain, but was tender on pressure. The vomiting still continued, and jaundice and epistaxis came on. He came to the hospital the next day, and was admitted. On the 28th the following notes were taken:-Patient is a well-nourished man, and presents an anxious, feverish appearance. He is jaundiced and breathing rapidly, the alæ nasi working. Respiration 44. There are no adventitious sounds in the chest. Pulse 100; not much tension. The apex beat is in the fifth space, nipple line, not diffused, and rather weak in character. Heart sounds normal. The tongue is red and dry. The patient has no appetite, and complains of great thirst. The temperature at night rose to $102 \cdot 6^{\circ}$. There is a slight prominence in the right lumbar region, extending. up into the right hypochondriac region; it is dull on percussion except in front, where colon resonance could be determined. The urine contains traces of albumen ano pus; it is tinged with bile; only about half an ounce. has been passed since admission. Vomiting still per. sists. Three stools have been evacuated containing bile.March 30th: Vomiting and hiccough still continue. $\mathrm{He}$ has passed $453 \mathrm{cc}$. of alkaline urine, containing bile, blood, and pus ; sp. gr. 1012, maximum temperature $100.6^{\circ}$.31st: The patient had a very bad night, being kept awake by hiccough and pain in the abdomen, commencing in the right flank and extending towards the epigastrium. The sickness still continues. He has passed $490 \mathrm{cc}$. of alkaline urine, containing blood, pus, and bile;. maximum temperature $101 \cdot 6^{\circ}$; preceded by a rigor. He has vomited some black, inky-looking fluid. His bowels. have acted, the motions being tarry. The vomiting and biccoughing continued during the night. - April lst: To-day he has been spitting bright-red blood, which is neutral in reaction and not aerated. Nearly the whole surface of the body is covered with a bright-red rash, which is in distinct spots and patches raised above the surface, and disappears on pressure. The patient says he feels much worse, pain in the abdomen being chiefly complained of. Urine dark, alkaline; sp. gr. 1012 ; contains 1.6 per cent. of urea ; blood, albumen, pus, and bile are present ; quantity, 249 ce. ; maximum temperature $97 \cdot 6^{\circ}$. - 2nd: Patient passed a bad night, being kept awake by the pain and hiccough. He has passed another tarry motion. His abdomen is more tense and rigid. The black vomit still continues. The rash is more marked, the spots having run into one another. There is no odema. Temperature $964^{\circ}$. Mr. Boyd was ealled in by Dr. Green to see the case. Hitherto only palliative treat. ment for non-obstructive jaundice had been adopted. As he was passing a not inconsiderable quantity of urine containing $1 \cdot 4$ per cent. of urea, and as there was a difference of opinion as to the primary cause of the symptoms, no operation was resorted to. In the ev ening he was seized with severe dyspnoea, and died quite suddenly before any remedies could be administered. He retained his intellectual faculties to the last, and muscular twitchings were not noticed.

Necropsy (made by Mr. Harold fourteen hours after death).-Body well nourished; skin jaundiced, and covered with the urticarial eruption. Heart: Weight $11 \mathrm{oz}$; nothing abnormal. Lungs: Notbing abnormal beyond an old pleuritic adhesion of the left. On opening the abdomen, the right kilney was found adherent to several coils of intestine. The pelvis was not dilated; but on removal of the intestines and stomach, and dissecting out the ureter, a stone. could be felt in it about an inch and a half beyond the pelvis. The organ was then removed ; it weighed $1 \mathrm{lb}$. $5 \mathrm{oz}$, and was. greatly hypertrophied. The capsule stripped easily. On slitting up the ureter, a small uric-acid caleulus of an irregular shape, measuring $\frac{2}{3}$ in. long by $\frac{1}{3}$ in. transverse diameter, was found impacted in the ureter an inch and a half from the hilus. The pelvis was not much dilated; $i$. beld barely half an ounce of water ; the calyces were very slightly dilated, and loose in one of them was a small uricacid calculus. The cortex measured from $\frac{1}{3}$ in. to $\frac{3}{4}$ in., and the pyramids $l$ in. to $1 \frac{1}{2}$ in. The medullary substance was red and of fairly good colour. The cortex was pale, and exhibited much yellowish mottling. There was no. trace of the left kidney, but there was some cicatricial tissue in the lumbar region. Liver : Weight $4 \mathrm{lb}$. 5oz. Its substance was of a pale yellowish-green colour, and was fairly firm; on section the bileducts were empty, and did not appear dilated. The gall-bladder only contained a little greyish white grumous fluid. There was no evidence of obstruction in the bile-ducts. The stomach and intestines showed no ulceration or erosion. 100 ce. of the blood was. 
taken, and placed in 200 cc. of rectified spirit to coagulate the proteids ; $90 \mathrm{cc}$. of this mixture was evaporated to dryness over a water-bath, and the residue boiled with water (filtered) to extract the nitrogenous crystalline substances. The filtrate represented the crystalline nitrogenous substances in $30 \mathrm{cc}$. of blood. This was evaporated to $5 \mathrm{cc}$., and the amount of nitrogen estimated by the hypobromiteof-soda method in a Dupré's apparatus ; 2.4 per cent. was read off, but inasmuch as the $30 \mathrm{cc}$. harl been reduced to 5 cc. this must be divided by 6 , and thus we obtain 0.4 per cent. of nitrogenous crystalline extractives in the blood. Another analysis was made, but instead of dissolving out the crystalline nitrogenous extractives with water absolute alcohol was used. Kreatin is almost insoluble in absolute alcohol; urea is very soluble. The alcoholic extract of the dried residue of a similar quantity of blood yielded 3 per cent. For the most part this would be urea, although some of the alcoholic extract, placed upon a slide and examined microscopically, showed numbers of tyrosin crystals; moreover, on addition of mercuric nitrate and mitric acid a faint red colouration was obtained, showing the presence of this body in traces. Portions of the liver and kidney were hardened in absolute alcohol, also in 2 per cent. bichromate of ammonia solution. Microscopical examination of sections of the kidney stained with methylene blue showed colonies of micrococci taking the form of cylinders in the uriniferous tubules and a general diffuse suppurative nephritis. Sections of the liver showed an acute inflammation of the portal canal, both amall and medium-sized, the branches of the portal veins being blocked with blood-corpuscles undergoing disintegracion. (Vide woodcut.) No leucin or tyrosin crystals were

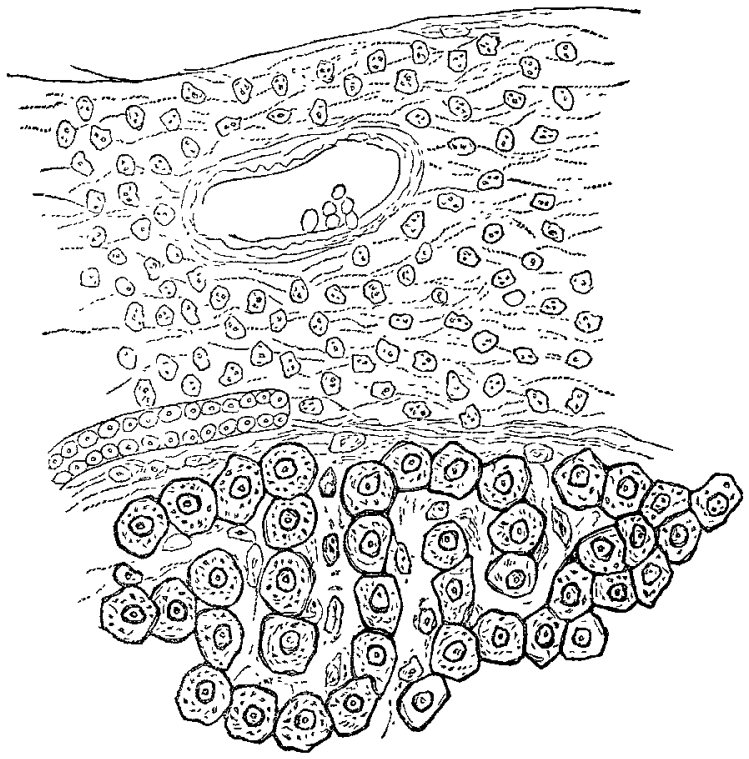

Section of liver showing small portion of portal canal. Magnified 300 diameters.

found in the liver section, but they were obtained in abundance from an aqueous extract of the organ.

The points of interest in this case are the following: 1. The hypertrophy of the kidney, for, although the enormous weight of $1 \mathrm{lb}$. oz. could be partly accounted for by the morbid condition, still it is highly probable that the organ had greatly increased in size as a compensation for the loss of the left kidney nine years previously. 2. The accurrence of urticaria is also of interest. I can only find one authority ${ }^{1}$ who has described this condition as occurring in jaundice; he met with a number of cases. 3. Non-obstructive jaundice as a result of the impaction of a renal calculus must be extremely rare, for $I$ can find no recorded case. Five days after the onset of symptoms jaundice came on, followed by black vomit, melwna, pyrexia, and rigors. At first I was inclined to attribute this to a toxemia due to the retention of nitrogenous waste products, but the fact that Sir William Roberts does not mention this as a complication and the presence of mierococci in the kidney in great numbers made me conclude that the non-obstructive jaundice was due to a pyæmic condition of the blood setting up pylephlebitis. Although the patient had an enormous excess of nitrogenous waste matter in the blood, it is probable that he died from a combination of causes, the principle of which were septie toxæmia and the non-elimination of nitrogenous eqaste products.

2 Graves' Clinical Medicine.

\section{ON THE TREATMENT OF TUBERCULAR DISEASE OF JOINTS.}

By HOWARD MARSH, F.R.C.S.,

ASSISTANT SURGEON AND LECTURER ON SURGERY AT ST. BAITHOLOMEW'S IIOSPITAL.

In The LANCET of Feb. 8th Mr. Croft published a lecture on the present stage of the treatment of tubercular disease of the joints, in which he enters upon a criticism of the figures and conclusions contained in the lectures I delivered last year at the College of Surgeons. In some parts of his remarks Mr. Croft, if his words are to be taken literally, travels a long way in the direction of indicating that my statements are not justified by the evidence which I produced. As I am sure, however, that he has not consciously gone beyond fair and friendly discussion, I shall keep to the facts of the case so far as I know them, and shall pass by expressions which I think it would have been better to recast.

The best treatment of surgical tnberculosis is obviously a subject of great interest and importance. Mr. Croft and Mr. Barker, to whom Mr. Croft frequentiy refers, hold that tubercular disease of the joints should be treated by early excision-that is, according to the former, "as soon as pus is known to be present, even if the surgeon is uncertain as to the condition of the bones"; according to the latter, "as soon as caseation is even suspected." And, further, that the operation should go wide of the disease. Mr. Croft states that "the facts on which the operationist party base their policy are something like these : that when tubercular disease commences in joint structures, it follows the same course as it does in other structures of the body; tiat it may cease to develop, and then undergo spontaneous cure; that it may develop and undergo caseous degeneration, and the caseous products may liquefy and give rise to abscess; that the local condition may be followed by infection of the other parts of the body ; that the tubercular element is artificially inoculable and is auto-inoculable, and this latter kind of infection may take place upon a long period of local quiescence." These facts call for a little close examination before they can be regarded as establishing the practice of early and free excision.

When we are told that in the joints, as in other struetures of the body, tubercular disease may undergo either spontaneous cure or lead to caseation and abscess, it becomes a crucial question in what proportion of cases these two results respectively occur. This question, however, Mr. Croft entirely ignores. Whether the proportion is as one to two or three, or as one to thirty or forty, or whether it can be influenced by treatment, he does not say. Nor does he give us any information as to the course which tuberculosis takes in other structures of the body - how often the disease ends in recovery, or how often it leads to destructive changes that cannot be arrested by any means short of complete removal of the affected structures by operative interference. Nor does he produce any evidence to show in what proportion of cases the local condition is followed by infection of other parts of the body. But it is obviously important to know whether general infection occurs frequently or rarely-once in every three or four cases, or once in every twenty or thirty. Then, what inference is to be drawn in regard to treatment from the fact that " the tubercular element is artificially inoculable"? The fact that a disease can be communicated by inoculation affords no measure of its dangers. Inoculation is the most direct method known for ensuring contagion ; but many diseases which are much more contagious than tuberculosis are wholly unimportant. Further, to state that tuberculosis is auto-inoculable is but to repeat, in other words, what Mr. Croft has already said-namely, that the local conditions may lead to infection of other parts, and it remains to ask, as before, in what proportion of cases this general infection occurs? Thus it will be seen that Mr. Croft advances as the grounds for early excision six propositions, which are either truisms in pathology or mere open possibilities of which he does not attempt any definite estimate. In the lectures which Mr. Croft is criticising I expressed the opinion that tuberculosis of the joints is much less formidable and intractable than many have supposed, and that if treatment by rest and its accessories is adopted early, and is adequately carried out, 